\title{
Ultraviolet Imaging of Volcanic Plumes: A New Paradigm in Volcanology
}

\author{
Andrew J. S. McGonigle 1,2,3,* (D), Tom D. Pering ${ }^{1}$ (D), Thomas C. Wilkes ${ }^{1}$ (D), \\ Giancarlo Tamburello ${ }^{4}$, Roberto $\mathrm{D}^{\prime}$ Aleo ${ }^{5}$, Marcello Bitetto ${ }^{5}$, Alessandro Aiuppa ${ }^{2,5}$ and \\ Jon R. Willmott 6 \\ 1 Department of Geography, University of Sheffield, Sheffield S10 2TN, UK; t.pering@sheffield.ac.uk (T.D.P.); \\ tcwilkes1@sheffield.ac.uk (T.C.W.) \\ 2 Istituto Nazionale di Geofisica e Vulcanologia, Sezione di Palermo, Via Ugo La Malfa 153, 90146 Palermo, \\ Italy; aiuppa@unipa.it \\ 3 School of Geosciences, The University of Sydney, Sydney NSW 2006, Australia \\ 4 Istituto Nazionale di Geofisica e Vulcanologia, Sezione di Bologna, Via Donato Creti, 12, 40100 Bologna, Italy; \\ giancarlo.tamburello@ingv.it \\ 5 DiSTeM, Università di Palermo, via Archirafi, 22, 90123 Palermo, Italy; roberto.daleo01@unipa.it (R.D.); \\ marcellobitetto@gmail.com (M.B.) \\ 6 Department of Electronic \& Electrical Engineering, University of Sheffield, Sheffield S1 4DE, UK; \\ j.r.willmott@sheffield.ac.uk \\ * Correspondence: a.mcgonigle@sheffield.ac.uk; Tel.: +44-114-222-7961
}

Academic Editors: Pasquale Sellitto, Giuseppe Salerno and Jesús Martínez Frías

Received: 1 April 2017; Accepted: 1 August 2017; Published: 8 August 2017

\begin{abstract}
Ultraviolet imaging has been applied in volcanology over the last ten years or so. This provides considerably higher temporal and spatial resolution volcanic gas emission rate data than available previously, enabling the volcanology community to investigate a range of far faster plume degassing processes than achievable hitherto. To date, this has covered rapid oscillations in passive degassing through conduits and lava lakes, as well as puffing and explosions, facilitating exciting connections to be made for the first time between previously rather separate sub-disciplines of volcanology. Firstly, there has been corroboration between geophysical and degassing datasets at $\approx 1 \mathrm{~Hz}$, expediting more holistic investigations of volcanic source-process behaviour. Secondly, there has been the combination of surface observations of gas release with fluid dynamic models (numerical, mathematical, and laboratory) for gas flow in conduits, in attempts to link subterranean driving flow processes to surface activity types. There has also been considerable research and development concerning the technique itself, covering error analysis and most recently the adaptation of smartphone sensors for this application, to deliver gas fluxes at a significantly lower instrumental price point than possible previously. At this decadal juncture in the application of UV imaging in volcanology, this article provides an overview of what has been achieved to date as well as a forward look to possible future research directions.
\end{abstract}

Keywords: ultraviolet cameras; volcanic plumes; interdisciplinary volcanology

\section{Introduction}

Volcanic activity is observed in a number of primary ways: firstly, by measurements of geophysical signatures, e.g., seismic, thermal, and acoustic; and secondly, through observations of gases released from summit craters, flanks, or fumaroles [1]; petrology also plays a key role here in respect of magma geochemistry. However, historically, the degassing data have been considered somewhat secondary to those from geophysics, in particular seismic data, largely because of limitations in the applied 
instrumentation. However, during the last two decades, there has been a major renaissance in volcanic gas monitoring, arising from the implementation of exciting new ground-based technologies for measuring the gases released in volcanic plumes. These approaches have been of utility in increasing our understanding of the underground processes that drive surface activity, as well as in routine volcano monitoring operations.

These recently applied techniques fall into two categories: firstly, those that concern the chemical composition of the gases, e.g., Fourier Transform Infrared (FTIR) spectroscopy [2] and MultiGAS units [3]; and secondly, those that capture emission rates or fluxes, for example correlation spectrometers (COSPECs), differential optical absorption spectrometers (DOAS units), and ultraviolet (UV) cameras. The emission rate data have been largely focused on sulphur dioxide $\left(\mathrm{SO}_{2}\right)$, which is straightforward to remotely sense in volcanic plumes due to its strong $\mathrm{UV}$ absorption bands and low ambient concentrations. There have also been exciting recent developments concerning laser LIght Detection And Ranging (LIDAR) remote sensing of carbon dioxide $\left(\mathrm{CO}_{2}\right)$ emissions, (e.g., [4,5]) from volcanoes.

UV remote sensing of $\mathrm{SO}_{2}$ emissions has been conducted since the 1970s, initially with COSPEC units developed for monitoring smokestack emissions from coal burning power stations, leading to the generation of a number of valuable long-term datasets [6,7]. Since the turn of the century, these units have been replaced with low cost USB-coupled linear array spectrometers, costing only a few thousand dollars, an order of magnitude less than COSPEC [8,9]. Data analysis to deliver $\mathrm{SO}_{2}$ column amounts is achieved using DOAS routines, and the units have been applied from mobile platforms, e.g., on cars and airplanes, whilst traversing beneath a plume, as well as in fixed position deployments involving scanning optics $[10,11]$. These scanning spectrometers are now in routine operation on numerous volcanoes worldwide $[12,13]$.

Notwithstanding the benefits of the above technology, and its service within the volcanology community, the flux data are limited in time resolution to a datum every $100 \mathrm{~s}$ or so, due to the requirement to physically scan or traverse the plume, which effectively provides time-integrated assessments of emissions on this timescale. This is too slow to resolve many rapid gas-driven volcanic processes, e.g., puffing and strombolian explosions, such that the acquired data cannot be used to investigate the driving underground fluid dynamics in these cases. Indeed, the only way to scrutinise these more rapid phenomena was via geophysical data, which are acquired at frequencies of at least $1 \mathrm{~Hz}$, leading to potentially a somewhat indirect proxy understanding. This prompted several research groups (e.g., [14,15]) to pioneer UV imaging approaches, which provide image snapshots of the plume gas column amounts every second or so, from which gas fluxes can be generated at the same time resolution. In this article, we cover the technological aspects of the application of UV imagery within volcanology, followed by an overview of the present and potential future scientific possibilities that this approach brings to the field.

\section{Ultraviolet Camera Instrumentation}

The UV camera's operation is based on imaging gas plumes, which arise from volcanic craters, vents, or fumarole fields, with a bandpass filter mounted to the fore of the unit, centered around $310 \mathrm{~nm}$, where $\mathrm{SO}_{2}$ absorbs incident radiation. Typically, imagery at a wavelength of around $330 \mathrm{~nm}$ is also acquired, where there is no $\mathrm{SO}_{2}$ absorption, to factor out broadband aerosol-related issues, which apply to both wavebands. This can be achieved using two co-aligned cameras, or a single camera, and a filter wheel. Below is a brief overview of the measurement approach, which is detailed further in Kantzas et al. [16], for the two cameras, two filter setup.

Firstly, optimal exposure settings are determined for each camera, based on the skylight illumination intensity, to maximize signal-to-noise and avoid saturation whilst viewing the sky. The next step is to measure dark images, at these exposure times, in order to account for the camera response when light is blocked from entering the fore-optics. Following this, background sky images are acquired for each camera by imaging a region of sky adjacent to the plume, e.g., containing no gas 
absorption. At this stage, the cameras are pointed at the plume and the measurement sequence begins. Following Beer's law, these images are processed to provide the uncalibrated apparent absorption, $A A$, for each pixel via the following relationship:

$$
A A=-\log _{10}\left[\frac{I P_{\mathrm{A}}-I D_{A}}{I B_{\mathrm{A}}-I D_{\mathrm{A}}} / \frac{I P_{\mathrm{NA}}-I D_{\mathrm{NA}}}{I B_{\mathrm{NA}}-I D_{\mathrm{NA}}}\right] .
$$

Here, $I P$ is the intensity whilst viewing the plume, $I B$ is the background sky intensity, and $I D$ is the dark intensity for the pixel in question, where the subscripts pertain to the camera filter wavelengths where there is $(A)$ and is not $(N A)$ absorption from the $\mathrm{SO}_{2}$, e.g., in the region of $310 \mathrm{~nm}$ and $330 \mathrm{~nm}$, respectively. Following the determination of the apparent absorption images, calibration is required. This can be achieved with quartz cells containing known column amounts of $\mathrm{SO}_{2}$. In this case, $A A$ values are determined for each cell and averaged over a section in the centre of the image. These data are plotted on a scatter plot of axes: cell column amount vs. apparent absorption. The slope of the best-fit line is then extracted, acting as the calibration factor, which all volcanic plume image pixel $A A$ values are then multiplied by. An alternative approach to calibration is to use a co-aligned spectrometer to determine a column amount value corresponding to a small section of the image to enable scaling to calibrated concentration values across the whole image. Once the calibrated images are generated, a cross-section line through the plume is defined, and all column amounts are integrated along this to determine the so-called integrated column amount. The plume speed is then found, often by determining an integrated column amount time series from cross-sections drawn through the plume at two different distances above the crater. These series are then cross-correlated to determine the temporal lag between them, from which the transit speed can be found $[17,18]$. Alternately, more sophisticated motion-tracking algorithms have also been applied [19], as has the correlation of temporally successive spatial series/longitudinal profiles of the plume to better exploit the available two-dimensional (2D) information in determining plume velocities [20]. Multiplication of the transport speed by one of the integrated column amount time series then leads to the generation of the flux time series.

Errors in flux computations are thought to be in the region of 20-30\% [21] for individual camera measurements. Furthermore, in a detailed inter-comparison of the performance characteristics of multiple camera units in establishing $\mathrm{SO}_{2}$ emissions, a one standard deviation precision of $20 \%$ was established for the ensemble of tested units [22]. Errors arise from the scattering of radiation between the sensor and the plume, e.g., light dilution, as well as scattering within the plume itself [23,24]. There are also uncertainties arising from cell calibration [25], as well as from light transit through the filters at different incident angles [26], which can cause the peak transmission wavelength to alter across the image. A further point relates to the requirement to image the plume at two wavelengths. Where this involves a single camera and a filter wheel, there will be a short time delay between the filter acquisitions. This will result in slight offsets between the plume locations in each case, due to the advection of the gases in the atmosphere, which can create issues in the retrieval. The use of dual cameras may also be problematic, as the retrieval is predicated on pixel-to-pixel correspondence between the imagery in both bands. In practice, this can be complicated by parallax effects: for deployments close to the plume, these are thermal and vibrational effects causing misalignments, as well as slight imperfections in the applied lenses, and non-identical optical settings for the cameras, e.g., in terms of the different applied filters. For this reason, the images can be shifted relative to one another in software in order to achieve the best possible spatial matching.

One approach that could mitigate against radiative transfer-related errors is a Fabry-Perot configuration $[27,28]$. Such optical devices allow light transmission at regularly spaced wavelengths, blocking the intervening radiation. In the context of volcanic $\mathrm{SO}_{2}$ measurements, the devices are tuned such that the interval between the peaks of this transmission spectrum corresponds to that between the peaks in the comb-like absorption spectrum of sulphur dioxide around $310 \mathrm{~nm}$. The devices can be set to sample radiation at these maxima in absorption, as well as the radiance in intervening wavelengths, 
and by comparing the two outputs, gas column amounts can be derived. To date, most of the UV imaging systems applied in volcanic $\mathrm{SO}_{2}$ measurements have been based on commercially available UV cameras, with price points of thousands of USD. Recently, however, low-cost sensors, designed primarily for the smartphone market, have been adapted for this application, such that a usable UV sensitivity of these units has been demonstrated [29], as well as adequate signal-to-noise characteristics for the $\mathrm{SO}_{2}$ monitoring application [30] (Figure 1).



Figure 1. Deployment of inexpensive smartphone sensor-based ultraviolet (UV) camera instrumentation (right) in tandem with more traditionally applied scientific grade cameras (left) on Mt. Etna. A false colour gas column amount inset image is included in the graphic, with scale to right, for the cheaper units, which were based on modified Raspberry Pi cameras (Raspberry Pi Foundation, Cambridge, UK). For further detail, see [29,30].

\section{Improving the Spatio-Temporal Resolution of Volcanic Degassing}

The cameras have now been deployed on a significant number of volcanoes worldwide, due in part to the convenience of being able to set up and operate from fixed positions during discrete field campaigns (e.g., [31,32]). To date, the targets covered by permanent network installations have been rather few, e.g., Etna and Stromboli in Italy and Kīlauea in Hawaii [33-37], potentially as a consequence of the requirement to image the plume, e.g., without cloud cover between the camera and summit area. There is, of course, meteorological cloud cover at the top of volcanoes, which can occlude observations. Herein lies one advantage of conventional spectroscopic gas flux assessments, in that imaging is not a requirement for this class of observation.

The cameras provide the possibility of resolving spatio-temporal degassing characteristics in unprecedented details. For instance, spatial information was typically only available heretofore from volcanoes with multiple craters, by the rare occurrence of walking traverse observations made very close to the source [38]. By gathering spatial information, the cameras implicitly provide scope for the resolution of gas fluxes from heterogenous sources, as exploited on Vulcano island (Italy), to measure gas fluxes from individual fumaroles [39]. This capability has also been exploited in respect of multiple vent scenarios, e.g., Fuego (Guatemala) [20] and Mt. Etna, where a shifting of degassing from one vent to another was observed in tandem with a transference of eruptive activity between craters [34].

In terms of temporal information, the UV cameras have enabled us to capture rapid trends in passive and explosive degassing. In particular, fluctuations in passive degassing on timescales of $10 \mathrm{~s}$ to $1000 \mathrm{~s}$ of seconds have been resolved using UV cameras [40], building on earlier observations of 
this phenomenon using a non-imaging dual spectrometer approach involving units with cylindrical lenses and quasi-horizontal fields of view [41,42]. Based on observations on Mt. Etna, Mayon (Philippines), and Erebus (Antarctica), using contemporaneous Multi-GAS observations and/or ancillary visible/near-infrared (IR) cameras, these fluctuations appear to also be manifested in the degassing of $\mathrm{CO}_{2}$ and water vapour emissions e.g., [43,44]. This behaviour has been observed in both conduit degassing scenarios (e.g., Mt. Etna) as well as from lava lakes. In terms of conduit degassing, arguments have been put forward that this behaviour arises from the arrangement of rising bubbles into layers of elevated gas concentrations, leading to periodic enhancements in passive non-overpressurised bubble bursting at the surface [40].

The situation with lava lakes is intriguing, in that rather different degassing trends have been observed from each of the volcanoes targeted to date with high time resolution gas flux observations, e.g., Villarrica, Chile [45], Kīlauea [46], and Erebus [42]. This potentially points to a wide variety of gas flow processes occurring across these systems, which range significantly, both in magmatic viscosities as well as in gas flux magnitudes. In particular, 'gas pistoning' is evident in the Kîlauea data, involving pronounced spikes in degassing, followed by a gradual waning in emissions, on timescales of tens of minutes, potentially caused by a gas accumulation and release mechanism. In contrast, the Erebus volcano demonstrates stable periodic degassing behaviour, present in both the acquired gas flux and gas composition time series [42], which is thought to arise from a stable bidirectional flow in the conduit, such that gas rich magma batches periodically rise, degas, then sink down again into the conduit. In Villarrica, gas flux time series data revealed no stable periodicity in degassing. This is thought to be precluded by turbulent mixing in the lava lake arising from continuous inflow of magma from the conduit [45].

One major application of the UV cameras has been to measure gas masses released during discrete explosions. Whilst this has been achieved spectroscopically with high temporal resolution differential optical absorption spectroscopy observations [41], and even with a correlation spectrometer [47], it is far easier to resolve these emissions with the cameras' imaging capacity. The eruptions where $\mathrm{SO}_{2}$ masses have been constrained with UV imagery have been ash-poor, strombolian, or weakly vulcanian events. Whilst the UV imaging of ash rich plumes has been acheived, yielding interesting insights into ash phase plume dynamics [48], the reduction in optical thickness caused by ash in these cases rules out the retrieval of $\mathrm{SO}_{2}$ emissions. Interestingly, these explosive UV camera studies typically point toward the non-explosive release of gas as being the dominant means by which these volcanoes release volatiles to the atmosphere [21,49-54], especially for basaltic open conduit cases, such as Etna and Stromboli in Italy, where gas bubbles are free to move through the melt. Indeed, in the Stromboli case, degassing was partitioned as $77 \%$ passive gas release (e.g., from spherical bubbles), $16 \%$ from puffing, e.g., from cap bubbles, and with only $7 \%$ from explosions, e.g., from gas slugs (Taylor bubbles) [49]. This study, incidentally, also constituted the first direct measurement of puffing gas masses from a volcano, pointing to the real benefits of the camera technology in terms of its high spatial resolution and sufficiently good sensitivity to capture these subtle degassing features.

In these reports, the subdivision of fluxing between the degassing classes appears to be most strongly tipped towards explosive release (although it is still often dominated by passive degassing) in the scenarios where eruptions are more vulcanian in nature [21,52-54], e.g., the Santiaguito (Guatemala), Asama (Japan), Semeru (Indonesia), and Fuego volcanoes. In particular, Smekens et al. [52] suggest, in respect of the Semeru observations, that accumulation and pressurisation beneath a viscous plug are in operation before breach and explosive release. This assertion is intuitive and follows on from that put forth following pioneering observations on the Karymsky volcano (Russia) by Fischer et al. [47], where a predominantly explosive gas release was reported based on correlation spectrometer observations made long before the advent of UV imaging. 


\section{Combination of UV Camera Degassing Data with Geophysical Data and Conduit Fluid Dynamics}

The above studies point to the absolute necessity of models to facilitate the interpretation of the acquired data. In this respect, the high time resolution of the UV cameras has an enormous benefit for volcanology. Specifically, the cameras can resolve gas release processes, which are caused by a variety of subterranean fluid dynamic mechanisms, which have been the subject of considerable prior numerical, mathematical, and laboratory modeling efforts within both the volcanic and engineering research communities. This is especially so in the case of strombolian explosions, which are thought to arise from the bursting of conduit filling gas slugs at the surface [55]. Here, at the very exciting current frontier in volcanology, UV camera data are enabling the first substantive bridging between the volcanic gas flux measurement and volcanic conduit fluid dynamic modeling communities.

In particular, in the first study of this nature, explosions on Stromboli were investigated, involving a tail or coda in emissions following the events [36]. The authors interpreted the activity, with the aid of computational fluid dynamic models, as arising from the fissioning of smaller "daughter" bubbles from the bases of the rising slugs (Figure 2). Furthermore, during a study of rapid $(0.25 \mathrm{~Hz})$ strombolian activity on Mt. Etna, explosive data were plotted on a scatter plot of repose time following the event vs. event mass [51]. An absence of large mass, long repose time data were noted, which was interpreted as being due to coalescence of adjacent rising slugs, e.g., leading to a longer repose interval before the arrival of the next distinct slug, and constituting the first direct empirical evidence of slug interaction in volcanic conduits. A follow-on report, based on thermal observations of puffing on Stromboli, also affirms the potential importance of this process in respect of cap bubbles [56].

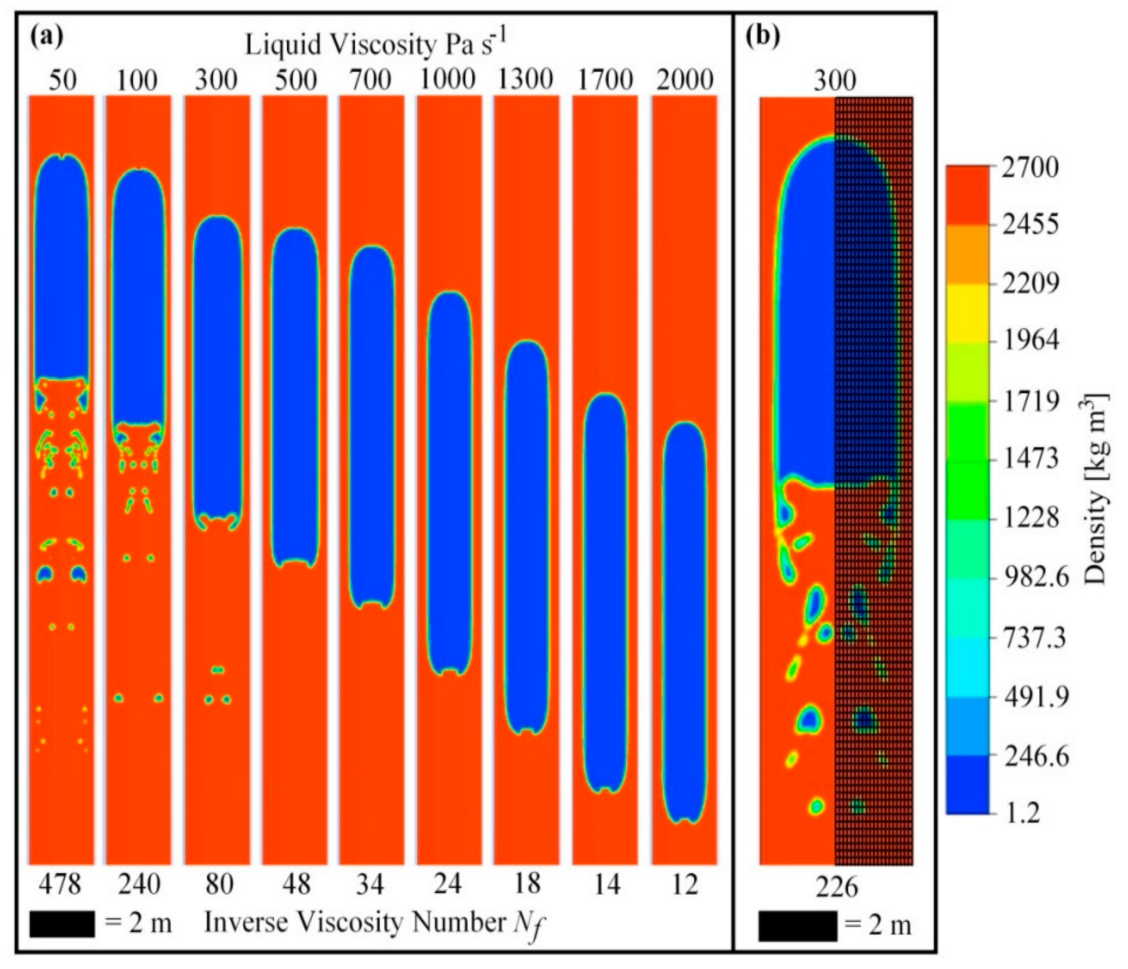

Figure 2. Computational fluid dynamic modeling of rising gas slugs on Stromboli, illustrating the fissuring of daughter bubbles from the slug base. This has been linked to codas in UV camera gas flux time series following strombolian explosions, illustrating the potential of combining models with high time resolution field degassing data to unravel the subterranean drivers of surface activity; (a) shows simulations for a range of fluid dynamical conditions e.g., in terms of liquid viscosity and inverse viscosity number, and (b) shows a zoom of behaviour for one such parameterisation; see main text and [36] for more detail. 
Another important benefit of the UV camera data is that the high time resolution gas fluxes can be compared with contemporaneous geophysical data, with far less aliasing than necessary previously; e.g., the latter data are acquired at frequencies $\geq 1 \mathrm{~Hz}$. This is highly significant in that many geophysical manifestations on volcanoes arise from gas-based processes, e.g., seismic signals are caused by the ascent of gas slugs in conduits, and thermal and infrasonic signatures are generated from the surficial bursting of these bubbles. Until now, we have had to rely purely on geophysical means to understand the rapid degassing processes on volcanoes, e.g., strombolian explosions and puffing. Not only do the UV camera data provide a more direct means of understanding these phenomena, but they also enable the possibility of making a far more direct comparison with geophysical series, which could lead the way towards a better interpretation of geophysical observations on volcanoes, and a more holistic understanding of volcanic behaviour.

The first report of high time resolution $(\approx 1 \mathrm{~Hz})$ degassing data being corroborated with geophysical data concerned explosions on the Stromboli volcano [41]. This study was performed using spectroscopy, rather than UV imaging, but, in common with a more recent UV camera study on this target [49], it revealed linear correlations between the magnitudes of the recorded degassing, thermal, and very long period (VLP) seismic signatures for the events. This fits with the conventionally held, although previously rather hypothetical, view that VLP signals on Stromboli arise from volumetric changes associated with the ascent of gas masses, e.g., slugs in the conduit, such that the larger the rising gas mass, the greater the VLP signal. Further related investigations have been performed on the Asama [53] and Fuego [54] volcanoes, where proportionality between VLP signals and released $\mathrm{SO}_{2}$ masses was also observed. The relative scaling of seismic moment with released $\mathrm{SO}_{2}$ mass, however, does not equate for all targets, which may be related to an absence of gas ratio information, e.g., the total released gas masses are not being considered. However, it is also highly likely that volcano-specific features, e.g., the conduit geometry, magma rheology, and the precise mechanism of VLP generation, which is likely to vary between the targets, will affect the degree to which the degassing processes are coupled into seismic energy in each case.

Ultraviolet imaging degassing fluxes have also been linked to tremor, a class of seismicity associated with pressure fluctuations in degassing magmas. Here, a number of studies have noted a relationship between these time series for the Etna, Fuego, and Kîlauea volcanoes, including conduit and lava lake degassing scenarios [20,40,44,46]. In one case, this has involved novel signal processing techniques based on wavelet analysis to isolate commonality in periodicity in pairs of geophysical datastreams [57]. These experimental outcomes are as would be expected, given that tremor is anticipated to increase with elevated bubble concentrations in magmas, or the more rapid flow of bubbles in the conduit, scenarios which would both correspond to periods of elevated gas release. In two of the studies, intriguing lag relationships were identified [20,44]. In particular, in Nadeau et al. [20], a trend of increasing temporal lags between the seismic and gas flux time series was observed in the period following explosions, implying perhaps that the source of seismic energy was becoming progressively deeper within the conduit due to the rheological stiffening of the magma downwards from the top of the column. In Pering et al. [44], bursts in $\mathrm{CO}_{2}$ outgassing were reported (derived from the UV cameras in tandem with Multi-GAS [3] units) which preceded spikes in seismicity, raising intriguing questions regarding the causal processes that might link these phenomena in this case.

Thermal observations have also been correlated with UV camera data, with the most detailed study to date in this area concerning explosions on Stromboli [49], which builds on an earlier more limited treatment on this target [41]. Both resulting articles demonstrated a linear relationship between these two parameters, although in the more recent one, two populations arose, corresponding to events, which were ash-free/with ash, respectively. This is as would be expected, e.g., the ashier eruptions will be thermally brighter due to the larger quantity of radiating solid ejecta. In addition, UV camera/high time resolution spectroscopic instrumentation-based attempts have been made to compare $\mathrm{SO}_{2}$ fluxes with acoustic data in respect of explosive activity, resulting in reports of either no [41] or somewhat 
limited [58] correlations being apparent between these time series. A significant breakthrough in this regard has come with the application of linear acoustic processing of the acquired infrasonic signals to infer gas masses. This methodology, which involves consideration of the entire waveform, and not merely the initial pressure conditions, led to 1:1 linear correlations with contemporaneously acquired UV camera-derived gas masses [35].

\section{Future Directions}

Ultraviolet camera technology provides an unprecedented opportunity to investigate volcanic degassing behaviour with far better spatial and temporal resolution than possible previously. This has expedited the linkage of gas fluxes with geophysical data and conduit fluid dynamic models in ways that were impossible previously, opening the path to a number of potentially very fruitful future research directions.

In particular, the comparison of high time resolution UV camera gas fluxes with modeled emission rates from laboratory and computational fluid dynamics is an area of study in its absolute infancy. By simulating degassing behaviour from a series of underground gas flow mechanisms, and comparing the results against field data to determine best matches, e.g., using correlative approaches, new avenues will be opened in terms of being able to understand how subterranean processes drive volcanism. We recently combined these approaches for the first time [38], illustrating the exciting scientific potential contained therein, in a study of strombolian activity on the Strombolian volcano. There is now much work remaining to be done in expanding this methodology to unravel degassing dynamics across a wide spectrum of activity styles and volcanic targets. This will encourage further developments in the models themselves, which have been somewhat focused on slug dynamics to date (e.g., [55]), to give greater attention to other potential fluid processes in volcanoes, e.g., bubbly, cap, annular, and churn flow mechanisms.

The linking of UV camera degassing data to geophysical data on timescales of $\approx 1 \mathrm{~Hz}$ has led to the establishment of correlations between degassing data and volcano-seismic and acoustic signals. This could enable the calibration of acquired acoustic and seismic signals to infer gas masses, thereby helping to overcome one of the key limitations of the UV camera approach, namely inoperability at night-time and when the plume cannot be imaged due to cloud cover $[35,53]$. Hence, whilst the UV cameras deliver the most direct estimates of the degassing output from volcanoes, these calibrated geophysical proxies could be used to straddle windows where the cameras cannot be used, enabling continuous monitoring to take place. Another dimension of corroboration between the geophysical and UV camera degassing signals will be to better understand how underground degassing processes are responsible for generating geophysical manifestations on volcanoes. A key aim here would be to attempt to identify $\approx 1 \mathrm{~Hz}$ multi-parametric (e.g., geophysical and degassing) signatures, which precede eruptions, to establish precursory templates. This will build on pioneering studies, which have already illustrated the profound scientific insights achievable by blending these disparate data, albeit on the basis of previously available coarse time resolution gas flux data (e.g., [59]). This linkage of ground based gas fluxes, models, and geophysical data will also mirror similar integrated initiatives to combine these approaches on the basis of satellite observations, which are enabling significant breakthroughs in volcanology [60].

Notwithstanding the capacity of camera observations to advance science, the uptake of this technology in routine monitoring, as opposed to discrete field campaign operation, has been somewhat limited in comparison with spectrometers employing DOAS retrieval algorithms. There are a number of reasons for this; for example, the requirement to image the plume does exclude observations under conditions where cloud obscures the gases. The lack of hyper-spectral data, unless the units are spectroscopically, rather than cell, calibrated, also provides less opportunity to mitigate against radiative transfer errors. One factor which might assist the further dissemination of the camera technology is the recent demonstration that order of magnitude cheaper smartphone sensor-based systems can be used in volcanic $\mathrm{SO}_{2}$ monitoring [29,30] (Figure 3). These units are so light that 
they could also be straightforwardly mounted on inexpensive drones available in the consumer electronics market for aerial observations to broaden the prior reach of drone-based volcanic gas surveillance [61,62]. There is, furthermore, the prospect of augmenting $\mathrm{UV} \mathrm{SO}_{2}$ imaging with thermal IR camera systems, which are capable of measuring $\mathrm{SO}_{2}$ (and ash) release by day and night, hence overcoming the limitation of the former spectral region in being reliant upon solar radiation [63].

Recently, we have briefly investigated the possible use of multi-band imaging to study plume gas ratios. This work was performed on the Stromboli volcano during 22-24 July 2015. Here, conventional $\mathrm{UV} \mathrm{SO} 2$ observations were made in tandem with near-IR $(\approx 900 \mathrm{~nm})$ imaging, in the latter case following the technique of Girona et al. [43], who posited that visible pixel brightness is quantitatively related to plume $\mathrm{H}_{2} \mathrm{O}$ abundance due to plume scattering from water-rich aerosol droplets. We thereby obtained uncalibrated $\mathrm{H}_{2} \mathrm{O} / \mathrm{SO}_{2}$ ratio images, demonstrating higher ratios for the fumarolic discharges vs. crater degassing, as would be expected. We furthermore measured the ratios associated with twenty explosions, and found that the $\mathrm{H}_{2} \mathrm{O} / \mathrm{SO}_{2}$ values were reduced systematically by some $50 \%$ relative to those during passive degassing, which follows the ratio decrease during such events noted in a prior Fourier transform infrared spectroscopy-based study on this volcano [64]. These results are very tentative, and in particular do not consider environmental effects which will significantly change the partitioning of the water between vapour and aerosol phases, with implications for the $\mathrm{H}_{2} \mathrm{O}$ retrievals, particularly when plume temperature changes, e.g., during explosions. Nevertheless, one can ascertain clear differences between fumarolic vs. crater degassing and the explosive vs. passive gas discharge signature in this case. Considerably more follow-on work would be required in order to establish whether calibrated and therefore quantitatively meaningful outputs could be achieved from this measurement approach.


Figure 3. Smartphone sensor (e.g., Rasperry Pi camera)-based UV imaging deployments on the Masaya volcano, Nicaragua, during June 2017. Measurement of the plume taken from outside the crater (left); measurements looking down at the lava lake surface (right).

A further possible research focus relates to the capacity of the cameras to image rates of volcanic gas-ambient air mixing, which are known to exert a key control on plume bromine monoxide $(\mathrm{BrO})$ chemistry $[65,66]$. To date, the atmospheric chemistry modeling approaches applied to investigate this phenomenon have been based on assumed Gaussian-type plume dispersion scenarios. Here, the capacity of the cameras to empirically capture the heterogeneity in plume dilution in the 'real world' could be of utility in helping to advance this area of science. This could, for example, build on prior work using imaging DOAS instrumentation to provide profile information of the $\mathrm{SO}_{2}$ and BrO column amounts in volcanic plumes [67]. The advantage of the cameras, however, in this case would be the ability to capture data faster than these alternate devices, as there is no requirement for the scanning of the spectrometer field of view across the image scene. 
Finally, there are fresh emerging strands in respect of attempting to better constrain and reduce errors associated with the measurements. In particular, recent work has been invested in better determining the plume transport direction in order to decrease uncertainty [68]. This is related to the fact that when viewing plumes obliquely, the overestimate in the associated integrated column amount is only offset by the underestimation in apparent plume speed in the case of slightly non-parallel views; for more extreme viewing scenarios appreciable error can result.

\section{Conclusions}

Ultraviolet imaging has been applied in volcanology over the last ten years or so, leading to step change improvements in our ability to resolve volcanic gas emissions, both in the temporal and spatial domain, with a user-friendly single point measurement configuration. This has led, in particular, to the capture of rapid gas flux trends associated with explosions, puffing, and passive degassing in a way that would have been simply impossible in the past. A number of groups have now developed UV camera instrumentation [22,69] and operating software [70], leading to constraints on gas release budgets and studies into a variety of degassing-driven processes on a wide range of volcanoes, worldwide. In addition, the cameras have the potential to lead to significant scientific breakthroughs by combining the acquired high temporal resolution degassing data with contemporaneous geophysical datasteams and models for underground gas flows. In recent years, we have seen the first steps towards realising these objectives, and evidence of the significant scientific value of these blended approaches. This article looks back at what has been achieved to date, and the considerable promise of UV plume imaging in volcanology going forward.

Acknowledgments: A.J.S.M. acknowledges a Leverhulme Trust Research Fellowship (RF-2016-580), the Rolex Awards for Enterprise and a Google Faculty Research Award (r/136958-11-1). T.D.P. acknowledges the support of a NERC studentship (NE/K500914/1), the University of Sheffield, and ESRC Impact Acceleration funding. T.C.W. acknowledges scholarship funding from the University of Sheffield. A.A., M.B., R.D. and G.T. acknowledge support from the European Research Council starting independent research grant (agreement 305377). We are most grateful to anonymous reviewers for the time they have taken to provide thoughtful and meaningful comments on an earlier version of this article.

Author Contributions: A.J.S.M., T.D.P. and T.C.W. wrote the paper. A.J.S.M., T.D.P., T.C.W., G.T., M.B., R.D., A.A. and J.R.W. were involved in designing the instrumentation, and performing the fieldwork and data analysis reported on here.

Conflicts of Interest: The authors declare no conflict of interest. The founding sponsors had no role in the design of the study; in the collection, analyses, or interpretation of data; in the writing of the manuscript, and in the decision to publish the results.

\section{References}

1. Fischer, T.P.; Chiodini, G. Volcanic, Magmatic and Hydrothermal Gases. In The Encyclopedia of Volcanoes, 2nd ed.; Sigurdsson, H., Houghton, B., McNutt, S.R., Rymer, H., Stix, J., Eds.; Academic Press: London, UK, 2015; pp. 779-798.

2. Notsu, K.; Mori, T.; Igarashi, G.; Tohjima, Y.; Wakita, H. Infrared spectral radiometer: A new tool for remote measurement of $\mathrm{SO}_{2}$ of volcanic gas. Geochem. J. 1993, 27, 361-366. [CrossRef]

3. Shinohara, H. A new technique to estimate volcanic gas composition: Plume measurements with a portable multi-sensor system. J. Volcanol. Geotherm. Res. 2005, 143, 319-333. [CrossRef]

4. Santoro, S.; Parracino, S.; Fioriani, L; D'Aleo, R.; Di Ferdinando, E.; Giudice, G.; Maio, G.; Nuvoli, M.; Aiuppa, A. Volcanic plume $\mathrm{CO}_{2}$ measurements at Mount Etna by mobile differential absorption Lidar. Geosciences 2017, 7, 9. [CrossRef]

5. Queißer, M.; Granieri, D.; Burton, M. A new frontier in $\mathrm{CO}_{2}$ flux measurements using a highly portable DIAL laser system. Sci. Rep. 2016, 6, 33834. [CrossRef] [PubMed]

6. Stoiber, R.E.; Malinconico, L.L.; Williams, S.N. Use of the correlation spectrometer at volcanoes. In Forecasting Volcanic Events; Tazieff, H., Sabroux, J.C., Eds.; Elsevier: Amsterdam, The Netherlands, 1983; pp. 425-444. 
7. Sutton, A.J.; Elias, T.; Gerlach, T.M.; Stokes, J.B. Implications for eruptive processes as indicated by sulfur dioxide emissions from Kilauea Volcano, Hawaii, 1979-1997. J. Volcanol. Geotherm. Res. 2001, 108, 283-302. [CrossRef]

8. McGonigle, A.J.S.; Oppenheimer, C.; Galle, B.; Mather, T.A.; Pyle, D.M. Walking traverse and scanning DOAS measurements of volcanic gas emission rates. Geophys. Res. Lett. 2002, 29, 461-464. [CrossRef]

9. Galle, B.; Oppenheimer, C.; Geyer, A.; McGonigle, A.J.S.; Edmonds, M.; Horrocks, L.A. A miniaturised UV spectrometer for remote sensing of $\mathrm{SO}_{2}$ fluxes: A new tool for volcano surveillance. J. Volcanol. Geotherm. Res. 2003, 119, 241-254. [CrossRef]

10. Edmonds, M.; Herd, R.A.; Galle, B.; Oppenheimer, C.M. Automated, high time-resolution measurements of $\mathrm{SO}_{2}$ flux at Soufrière Hills Volcano, Montserrat. Bull. Volcanol. 2003, 65, 578-586. [CrossRef]

11. McGonigle, A.J.S.; Oppenheimer, C.; Hayes, A.R.; Galle, B.; Edmonds, M.; Caltabiano, T.; Salerno, G.; Burton, M.; Mather, T.A. Sulphur dioxide flux measurements at Mount Etna, Vulcano and Stromboli measured with an automated scanning static ultraviolet spectrometer. J. Geophys. Res. 2003, 108, 2455. [CrossRef]

12. Salerno, G.G.; Burton, M.R.; Oppenheimer, C.; Caltabiano, T.; Randazzo, D.; Bruno, N.; Longo, V. Three-years of $\mathrm{SO}_{2}$ flux measurements of Mt. Etna using an automated UV scanner array: Comparison with conventional traverses and uncertainties in flux retrieval. J. Volcanol. Geotherm. Res. 2009, 183, 76-83. [CrossRef]

13. Galle, B.; Johansson, M.; Rivera, C.; Zhang, Y.; Kihlman, M.; Kern, C.; Lehmann, T.; Platt, U.; Arellano, S.; Hidalgo, S. Network for Observation of Volcanic and Atmospheric Change (NOVAC) - A global network of volcanic gas monitoring: Network layout and instrument description. J. Geophys. Res. 2010, 115, D05304. [CrossRef]

14. Mori, T.; Burton, M.R. The $\mathrm{SO}_{2}$ camera: A simple, fast and cheap method for ground-based imaging of $\mathrm{SO}_{2}$ in volcanic plumes. Geophys. Res. Lett. 2006, 33. [CrossRef]

15. Bluth, G.; Shannon, J.; Watson, I.M.; Prata, A.J.; Realmuto, V. Development of an ultra-violet digital camera for volcanic $\mathrm{SO}_{2}$ imaging. J. Volcanol. Geotherm. Res. 2007, 161, 47-56. [CrossRef]

16. Kantzas, E.P.; McGonigle, A.J.S.; Tamburello, G.; Aiuppa, A.; Bryant, R.G. Protocols for UV camera volcanic $\mathrm{SO}_{2}$ measurements. J. Volcanol. Geotherm. Res. 2010, 194, 55-60. [CrossRef]

17. Williams-Jones, G.; Horton, K.A.; Elias, T.; Garbeil, H.; Mouginis-Mark, P.J.; Sutton, A.J.; Harris, A.J.L. Accurately measuring volcanic plume velocity with multiple UV spectrometers. Bull. Volcanol. 2006, 68, 328-332. [CrossRef]

18. McGonigle, A.J.S.; Hilton, D.R.; Fischer, T.P.; Oppenheimer, C. Plume velocity determination for volcanic $\mathrm{SO}_{2}$ flux measurements. Geophys. Res. Lett. 2005, 32, L11302. [CrossRef]

19. Peters, N.; Hoffmann, A.; Barnie, T.; Herzog, M.; Oppenheimer, C. Use of motion estimation algorithms for improved flux measurements using $\mathrm{SO}_{2}$ cameras. J. Volcanol. Geotherm. Res. 2015, 300, 58-69. [CrossRef]

20. Nadeau, P.A.; Palma, J.L.; Waite, G.P. Linking volcanic tremor, degassing, and eruption dynamics with $\mathrm{SO}_{2}$ imaging. Geophys. Res. Lett. 2011, 38, L013404. [CrossRef]

21. Holland, A.S.P.; Watson, I.M.; Phillips, J.C.; Caricchi, L.; Dalton, M.P. Degassing processes during lava dome growth: Insights from Santiaguito Lava Dome, Guatemala. J. Volcanol. Geotherm. Res. 2011, 202, 153-166. [CrossRef]

22. Kern, C.; Lübcke, P.; Bobrowski, N.; Campion, R.; Mori, T.; Smekens, J.-F.; Stebel, K.; Tamburello, G.; Burton, M.R.; Platt, U.; et al. Intercomparison of $\mathrm{SO}_{2}$ camera systems for imaging volcanic gas plumes. J. Volcanol. Geotherm. Res. 2015, 300, 22-36. [CrossRef]

23. Campion, R.A.; Delgado-Granados, H.; Mori, T. Image-based correction of the light dilution effect for $\mathrm{SO}_{2}$ camera measurements. J. Volcanol. Geotherm. Res. 2015, 300, 48-57. [CrossRef]

24. Kern, C.; Werner, C.; Elias, T.; Sutton, A.J.; Lübcke, P. Applying UV cameras for $\mathrm{SO}_{2}$ detection to distant or optically thick volcanic plumes. J. Volcanol. Geotherm. Res. 2013, 262, 80-89. [CrossRef]

25. Lübcke, P.; Bobrowski, N.; Illing, S.; Kern, C.; Alvarez Nieves, J.M.; Vogel, L.; Zielcke, J.; Delgado Granados, H.; Platt, U. On the absolute calibration of $\mathrm{SO}_{2}$ cameras. Atmos. Meas. Tech. 2013, 6, 677-696. [CrossRef]

26. Kern, C.; Kick, F.; Lübcke, P.; Vogel, L.; Wöhrbach, M.; Platt, U. Theoretical description of functionality, applications, and limitations of $\mathrm{SO}_{2}$ cameras for the remote sensing of volcanic plumes. Atmos. Meas. Tech. 2010, 3, 733-749. [CrossRef] 
27. Kuhn, J.; Bobrowski, N.; Lübcke, P.; Vogel, L.; Platt, U. A Fabry-Perot interferometer-based camera for two-dimensional mapping of $\mathrm{SO}_{2}$ distributions. Atmos. Meas. Tech. 2014, 7, 3705-3715. [CrossRef]

28. Platt, U.; Lübcke, P.; Kuhn, J.; Bobrowski, N.; Prata, F.; Burton, M.; Kern, C. Quantitative imaging of volcanic plumes-Results, needs, and future trends. J. Volcanol. Geotherm. Res. 2015, 300, 7-21. [CrossRef]

29. Wilkes, T.C.; McGonigle, A.J.S.; Pering, T.D.; Taggart, A.J.; White, B.S.; Bryant, R.G.; Willmott, J.R. Ultraviolet Imaging with Low Cost Smartphone Sensors: Development and Application of a Raspberry Pi-Based UV Camera. Sensors 2016, 16, 1649. [CrossRef] [PubMed]

30. Wilkes, T.C.; Pering, T.D.; McGonigle, A.J.S.; Tamburello, G.; Willmott, J.R. A low cost smartphone sensor-based UV camera for volcanic $\mathrm{SO}_{2}$ emission measurements. Remote Sens. 2017, 9, 27. [CrossRef]

31. Campion, R.; Martinez-Cruz, M.; Lecocq, T.; Caudron, C.; Pacheco, J.; Pinardi, G.; Hermans, C.; Carn, S.; Bernard, A. Space- and ground-based measurements of sulphur dioxide emissions from Turrialba Volcano (Costa Rica). Bull. Volcanol. 2012, 74, 1757-1770. [CrossRef]

32. Stebel, K.; Amigo, A.; Thomas, H.E.; Prata, A.J. First estimates of fumarolic $\mathrm{SO}_{2}$ fluxes from Putana volcano, Chile, using an ultraviolet imaging camera. J. Volcanol. Geotherm. Res. 2015, 300, 112-120. [CrossRef]

33. Kern, C.; Sutton, J.; Elias, T.; Lee, L.; Kamibayashi, K.; Antolik, L. An automated $\mathrm{SO}_{2}$ camera system for continuous, real-time monitoring of gas emissions from Kīlauea Volcano's summit Overlook Crater. J. Volcanol. Geotherm. Res. 2015, 300, 81-94. [CrossRef]

34. D'Aleo, R.; Bitetto, M.; Delle Donne, D.; Tamburello, G.; Battaglia, A.; Coltelli, M.; Patanè, D.; Prestifilippo, M.; Sciotto, M.; Aiuppa, A. Spatially resolved $\mathrm{SO}_{2}$ flux emissions from Mt Etna. Geophys. Res. Lett. 2016, 43, 7511-7519. [CrossRef] [PubMed]

35. Delle Donne, D.; Ripepe, M.; Lacanna, G.; Tamburello, G.; Bitetto, M.; Aiuppa, A. Gas mass derived by infrasound and UV cameras: Implications for mass flow rate. J. Volcanol. Geotherm. Res. 2016, 325, 169-178. [CrossRef]

36. Pering, T.D.; McGonigle, A.J.S.; James, M.R.; Tamburello, G.; Aiuppa, A.; Delle Donne, D.; Ripepe, M. Conduit dynamics and post explosion degassing on Stromboli: A combined UV camera and numerical modelling treatment. Geophys. Res. Lett. 2016, 43, 5009-5016. [CrossRef] [PubMed]

37. Burton, M.R.; Salerno, G.G.; D’Auria, L.; Caltabiano, T.; Murè, F.; Maugeri, R. $\mathrm{SO}_{2}$ flux monitoring at Stromboli with the new permanent INGV SO 2 camera system: A comparison with the FLAME network and seismological data. J. Volcanol. Geotherm. Res. 2015, 300, 95-102. [CrossRef]

38. Aiuppa, A.; Giudice, G.; Gurrieri, S.; Liuzzo, M.; Burton, M.; Caltabiano, T.; McGonigle, A.J.S.; Salerno, G.; Shinohara, H.; Valenza, M. Total volatile flux from Mount Etna. Geophys. Res. Lett. 2008, 35, L24302. [CrossRef]

39. Tamburello, G.; Kantzas, E.P.; McGonigle, A.J.S.; Aiuppa, A.; Giudice, G. UV camera measurements of fumarole field degassing (La Fossa crater, Vulcano Island). J. Volcanol. Geotherm. Res. 2011, 199, 47-52. [CrossRef]

40. Tamburello, G.; Aiuppa, A.; McGonigle, A.J.S.; Allard, P.; Cannata, A.; Giudice, G.; Kantzas, E.P.; Pering, T.D. Periodic volcanic degassing behavior: The Mount Etna example. Geophys. Res. Lett. 2013, 40, 4818-4822. [CrossRef]

41. McGonigle, A.J.S.; Aiuppa, A.; Ripepe, M.; Kantzas, E.P.; Tamburello, G. Spectroscopic capture of $1 \mathrm{~Hz}$ volcanic $\mathrm{SO}_{2}$ fluxes and integration with volcano geophysical data. Geophys. Res. Lett. 2009, 36, L21309. [CrossRef]

42. Boichu, M.; Oppenheimer, C.; Tsanev, V.; Kyle, P.R. High temporal resolution $\mathrm{SO}_{2}$ flux measurements at Erebus volcano, Antarctica. J. Volcanol. Geotherm. Res. 2010, 190, 325-336. [CrossRef]

43. Girona, T.; Costa, F.; Taisne, B.; Aggangan, B.; Ildefonso, S. Fractal degassing from Erebus and Mayon volcanoes revealed by a new method to monitor $\mathrm{H}_{2} \mathrm{O}$ emission cycles. J. Geophys. Res. Solid Earth 2015, 120, 2988-3002. [CrossRef]

44. Pering, T.D.; Tamburello, G.; McGonigle, A.J.S.; Aiuppa, A.; Cannata, A.; Giudice, G.; Patanè, D. High time resolution fluctuations in volcanic carbon dioxide degassing from Mount Etna. J. Volcanol. Geotherm. Res. 2014, 270, 115-121. [CrossRef]

45. Moussallam, Y.; Bani, P.; Curtis, A.; Barnie, T.; Moussallam, M.; Peters, N.; Schipper, C.I.; Aiuppa, A.; Giudice, G.; Amigo, Á.; et al. Sustaining persistent lava lakes: Observations from high-resolution gas measurements at Villarrica volcano, Chile. Earth Planet. Sci. Lett. 2016, 454, 237-247. [CrossRef] 
46. Nadeau, P.A.; Werner, C.; Waite, G.P.; Carn, S.A.; Brewer, I.D.; Elias, T.; Sutton, A.J.; Kern, C. Using $\mathrm{SO}_{2}$ camera imagery to examine degassing and gas accumulation at Kīlauea volcano. J. Volcanol. Geotherm. Res. 2015, 300, 103-111. [CrossRef]

47. Fischer, T.P.; Roggensack, K.; Kyle, P.R. Open and almost shut case for explosive eruptions: Vent processes determined by $\mathrm{SO}_{2}$ emission rates at Karymsky volcano, Kamchatka. Geology 2002, 30, 1059-1062. [CrossRef]

48. Yamamoto, H.; Watson, I.M.; Phillips, J.C.; Bluth, G.J. Rise dynamics and relative ash distribution in vulcanian eruption plumes at Santiaguito Volcano, Guatemala, revealed using an ultraviolet imaging camera. Geophys. Res. Lett. 2008, 35, L08314. [CrossRef]

49. Tamburello, G.; Aiuppa, A.; Kantzas, E.P.; McGonigle, A.J.S.; Ripepe, M. Passive vs. active degassing modes at an open-vent volcano (Stromboli, Italy). Earth Planet. Sci. Lett. 2012, 359, 106-116. [CrossRef]

50. Mori, T.; Burton, M. Quantification of the gas mass emitted during single explosions on Stromboli with the $\mathrm{SO}_{2}$ imaging camera. J. Volcanol. Geotherm. Res. 2009, 188, 395-400. [CrossRef]

51. Pering, T.D.; Tamburello, G.; McGonigle, A.J.S.; Aiuppa, A.; James, M.R.; Lane, S.J.; Sciotto, M.; Cannata, A.; Patanè, D. Dynamics of mild strombolian activity on Mt. Etna. J. Volcanol. Geotherm. Res. 2015, 300, 103-111. [CrossRef]

52. Smekens, J.-F.; Clarke, A.B.; Burton, M.R.; Harijoko, A.; Wibowo, H. $\mathrm{SO}_{2}$ emissions at Semeru volcano, Indonesia: Characterization and quantification of persistent periodic explosive activity. J. Volcanol. Geotherm. Res. 2015, 300, 121-128. [CrossRef]

53. Kazahaya, R.; Mori, T.; Takeo, M.; Ohminato, T.; Urabe, T.; Maeda, Y. Relation between single very-long-period pulses and volcanic gas emissions at Mt. Asama, Japan. Geophys. Res. Lett. 2011, 38, L11307. [CrossRef]

54. Waite, G.P.; Nadeau, P.A.; Lyons, J.J. Variability in eruption style and associated very long period events at Fuego volcano, Guatemala. J. Geophys. Res. Solid Earth 2013, 118, 1526-1533. [CrossRef]

55. James, M.R.; Lane, S.J.; Wilson, L.; Corder, S.B. Degassing at low magma-viscosity volcanoes: Quantifying the transition between passive bubble-burst and Strombolian eruption. J. Volcanol. Geotherm. Res. 2009, 180, 81-88. [CrossRef]

56. Gaudin, D.; Taddeucci, J.; Scarlato, P.; Harris, A.; Bombrun, M.; Del Bello, E.; Ricci, T. Characteristics of puffing activity revealed by ground-based, thermal infrared imaging: The example of Stromboli volcano (Italy). Bull. Volcanol. 2007, 79, 24. [CrossRef]

57. Pering, T.D.; Tamburello, G.; McGonigle, A.J.S.; Hanna, E.; Aiuppa, A. Correlation of oscillatory behaviour in Matlab using wavelets. Comput. Geosci. 2014, 70, 206-212. [CrossRef]

58. Dalton, M.P.; Waite, G.P.; Watson, I.M.; Nadeau, P.A. Multiparameter quantification of gas release during weak Strombolian eruptions at Pacaya Volcano, Guatemala. Geophys. Res. Lett. 2010, 37, L09303. [CrossRef]

59. Fischer, T.P.; Morrissey, M.M.; Calvache, M.L.V.; Gómez, D.M.; Torres, R.C.; Stix, J.; Williams, S.N. Correlations between $\mathrm{SO}_{2}$ flux and long-period seismicity at Galeras volcano. Nature 1994, 368, 135-137. [CrossRef]

60. McCormick Kilbride, B.; Edmonds, M.; Biggs, J. Observing eruptions of gas-rich compressible magmas from space. Nat. Commun. 2016, 7, 13744. [CrossRef] [PubMed]

61. McGonigle, A.J.S.; Aiuppa, A.; Guidice, G.; Tamburello, G.; Hodson, A.J.; Gurrieri, S. Unmanned aerial vehicle measurements of volcanic carbon dioxide fluxes. Geophys. Res. Lett. 2008, 35, L06303. [CrossRef]

62. Xi, X.; Johnson, M.S.; Jeong, S.; Fladeland, M.; Pieri, D.; Diaz, J.A.; Bland, G.L. Constraining the sulfur dioxide degassing flux from Turrialba volcano, Costa Rica using unmanned aerial system measurements. J. Volcanol. Geotherm. Res. 2016, 325, 110-118. [CrossRef]

63. Lopez, T.; Thomas, H.; Prata, A.J.; Amigo, A.; Fee, D.; Moriano, D. Volcanic Plume Characteristics Determined Using an Infrared Imaging Camera. J. Volcanol. Geotherm. Res. 2015, 300, 148-166. [CrossRef]

64. Burton, M.; Allard, P.; Muré, F.; La Spina, A. Magmatic gas composition reveals the source depth of slug-driven strombolian explosive activity. Science 2007, 317, 227. [CrossRef] [PubMed]

65. Von Glasow, R. Atmospheric chemistry in volcanic plumes. Proc. Natl. Acad. Sci. USA 2010, 107, 6594-6599. [CrossRef] [PubMed]

66. Roberts, T.J.; Martin, R.S.; Jourdain, L. Reactive bromine chemistry in Mount Etna's volcanic plume: The influence of total $\mathrm{Br}$, high-temperature processing, aerosol loading and plume-air mixing. Atmos. Chem. Phys. 2014, 14, 11201-11219. [CrossRef] 
67. Loubain, I.; Bobrowski, N.; Rouwet, D.; Inguaggiato, S.; Platt, U. Imaging DOAS for volcanological applications. Bull. Volcanol. 2009, 71, 753-765. [CrossRef]

68. Klein, A.; Lübcke, P.; Bobrowski, N.; Kuhn, J.; Platt, U. Plume propagation direction determination with $\mathrm{SO}_{2}$ cameras. Atmos. Meas. Tech. 2017, 10, 979-987. [CrossRef]

69. Burton, M.R.; Prata, F.; Platt, U. Volcanological applications of $\mathrm{SO}_{2}$ cameras. J. Volcanol. Geotherm. Res. 2015, 300, 2-6. [CrossRef]

70. Tamburello, G.; Kantzas, E.P.; McGonigle, A.J.S.; Aiuppa, A. Vulcamera: A program for measuring volcanic $\mathrm{SO}_{2}$ using UV cameras. Ann. Geophys. 2011, 54, 219-221. [CrossRef]

(C) 2017 by the authors. Licensee MDPI, Basel, Switzerland. This article is an open access article distributed under the terms and conditions of the Creative Commons Attribution (CC BY) license (http://creativecommons.org/licenses/by/4.0/). 